\title{
VIDAS ININTELIGÍVEIS E PRÁTICAS INDIZÍVEIS: TRAVESTIS BRASILEIRAS NEGOCIANDO AS POSIÇÕES ENTRE CRIMINALIZAÇÃO E VITIMIZAÇÃO DA ORGANIZAÇÃO DAS REDES DE PROSTITUIÇÃO
}

UNINTELLIGIBLE LIVES AND UNSPEAKABLE PRACTICES: BRAZILIAN TRAVESTIS NEGOTIATING POSITIONS BETWEEN CRIMINALISATION AND VICTIMISATION WITHIN ORGANISED PROSTITUTION NETWORKS

\author{
Joseli Maria Silva ', Marcio Jose Ornat ${ }^{1}$ \\ ${ }^{1}$ Universidade Estadual de Ponta Grossa (UEPG), Ponta Grossa, PR, Brasil
}

Correspondência para: Marcio Jose Ornat (geogenero@gmail.com)

doi: 10.12957/geouerj.2018.29601

Recebido em: 14 jul. 2017 | Aceito em: 18 dez. 2018

\section{$\checkmark$ iThenticate}

\section{RESUMO}

Este artigo tem por objetivo evidenciar a criminalização das travestis brasileiras e as formas de organização de sua sobrevivência por meio das redes de prostituição. Para tanto, o texto explora as contradições entre a compreensão do grupo sobre suas vivências e os esquemas normativos de inteligibilidade do comércio sexual, tanto na escala nacional como internacional. Os dados são oriundos de trinta e duas entrevistas em profundidade. Sete delas realizadas com responsáveis por Organizações Não Governamentais (ONGs) brasileiras. Três com instituições espanholas envolvidas com a situação da prostituição envolvendo imigrantes e vinte e duas entrevistas com travestis brasileiras no período de 2008 a 2010. A análise evidência que as redes de prostituição travesti brasileiras são criminalizadas e pouco inteligíveis pelas instituições formais, aumentando assim sua vulnerabilidade social.

Palavras-chave: Redes de Prostituição; Vidas precárias; Criminalização; Travestis Brasileiras.

\begin{abstract}
This article highlights the criminalisation of Brazilian travestis and the organised forms in which they survive within prostitution networks. The article explores the contradictions between the understanding of travestis about their experiences and the normative frameworks of intelligibility within the sex trade, both within Brazil and abroad. The data was obtained from thirty-two in-depth interviews. Seven of the latter were conducted by Brazilian non-governmental organisations (NGOs). Three were conducted by Spanish institutions dealing with prostitution involving immigrants, and the remaining twenty-two interviews were conducted with Brazilian travestis during the period 2008-2010. The analysis shows that Brazilian travestis who work within prostitution networks are criminalised. Their situation is little understood by formal institutions, thereby increasing their social vulnerability.
\end{abstract}

Keywords: Prostitution Networks; Precarious Lives; Criminalisation; Brazilian Travestis.

\section{Introdução}

O início do século XXI foi marcado pelo aumento das discussões em torno do comércio sexual e a imigração em todo o mundo. Várias dinâmicas migratórias foram associadas aos mecanismos do tráfico de seres humanos, levantando uma série de polêmicas em torno desta correlação (AUGUSTÍN, 2007; 
GRUPO DAVIDA, 2005; KEMPADOO, 2005; KEMPADO0, SANGHERA e PATTANAIK, 2005; KARRAKER, 2013; SHARMA, 2005). O Brasil, um dos principais países de origem de pessoas consideradas traficadas para fins de exploração sexual, elaborou o I Plano Nacional Contra o Tráfico de Seres Humanos em 2006 a fim de responder as demandas das políticas internacionais ${ }^{1}$. Nesse contexto, várias dinâmicas de comércio de serviços sexuais passaram a ser objeto de discussão na sociedade brasileira, inclusive as ações realizadas pelas travestis ${ }^{2}$.

Apesar de suas vidas precárias, no sentido proposto por Butler (2004b), as travestis estabelecem uma série de estratégias e constroem espacialidades próprias para tornar suas vidas vivíveis. Uma delas é a instituição de redes de prostituição nacionais e internacionais, onde a maioria delas brasileiras conseguem seu sustento econômico e, a outra, é a constituição de Organizações Não Governamentais ${ }^{3}$ que lutam por direitos humanos.

As políticas internacionais para contenção de fluxos migratórios de pessoas para fins de comércio sexual têm apontado as Organizações Não Governamentais (ONGs) dos países de origem como agentes fundamentais no desenvolvimento de ações de prevenção de tal prática. A lógica universalizante de tais políticas, contudo, despreza a organização específica de travestis brasileiras e suas estratégias de lutas, frustrando as ações preventivas da imigração de travestis para o comércio sexual, notadamente na Europa.

Nesse sentido, este texto analisa os paradoxos entre os esquemas normativos da inteligibilidade da organização das redes de prostituição de travestis brasileiras e a forma como elas próprias compreendem suas práticas a fim de tornar suas vidas vivíveis. Os argumentos que são apresentados

\footnotetext{
${ }^{1}$ O Brasil é signatário do Protocolo de Palermo lançado em 2000 na convenção das Nações Unidas contra o Crime Organizado Transnacional e entrou em vigor em 29 de setembro de 2003.

2 Travetis são pessoas que são designadas como homens no nascimento, mas vivem de acordo com o sexo feminino. Elas realizam uma série de mudanças corporais para ajudar seus corpos a conseguir uma aparência feminina. Lewis (2010) argumenta que os termos "travesti" e "transgender" não são permutáveis porque fazem parte de diferentes tradições culturais e linguísticas.

${ }^{3}$ A Articulação Nacional de Travestis e Transexuais (ANTRA) é uma entidade que abriga mais de 178 ONGs de travestis e transexuais em todo o país. Fonte: http://www.alegriafalhada.com.br/antra-articulacao-nacional-de-travestis-e-transexuaissolicita-que-se-trate-travestis-no-feminino/
} 
aqui estão baseados em trinta e duas entrevistas em profundidade. Sete delas com responsáveis por ONGs que contemplam travestis, três com instituições espanholas inseridas no contexto de discussão sobre prostituição envolvendo imigrantes e vinte e duas entrevistas com travestis brasileiras, sendo dez realizadas na Espanha e doze no Brasil no período de 2008 e 2010.

Os resultados da pesquisa estão organizados em três partes. Na primeira parte é realizada uma abordagem da lógica desumanizadora das travestis na sociedade brasileira e a naturalização da prostituição como forma de sobrevivência. Na segunda parte são exploradas as formas de pensamento que estruturam as políticas que envolvem a organização das redes de prostituição travesti brasileira. Na terceira parte será privilegiada a reflexibilidade das travestis sobre suas estratégias para tornar suas vidas vivíveis.

\section{As Vidas Precárias de Travestis Profissionais do Sexo no Brasil}

Apesar de não haver no Brasil estudos sistemáticos sobre a expectativa de vida média das travestis, Antunes (2010) afirma que seja de 35 anos de idade. A Organização Não Governamental Transgender Europe, que monitora os assassinatos de pessoas trans no mundo, afirmam que o Brasil é o país que mais reporta crimes de ódio (BALZER, HUTTA, ADRIÁN, HYLDAL, STRYKER, 2012). A Organização Não Governamental brasileira Grupo Gay da Bahia comunica em seu relatório de 2014 que nesse ano houve um total de 326 assassinatos de pessoas da comunidade LGBT no Brasil, sendo que, 134 deles foram de travestis.

A morte das travestis brasileiras e sua baixa expectativa de vida é apenas o fato mais visível daquilo que Butler (2004a) chama de violência normativa. A norma tem o poder que potencializa ou restringe a vida, produz violência sobre aqueles que, ao não se conformarem à norma, tornam-se ininteligíveis e não existentes e, sendo assim, as travestis brasileiras vivem a vida sendo mortas socialmente.

A sociedade brasileira estrutura uma política em que escolhem pela morte física das travestis ao negar sua existência em várias esferas da vida, como argumenta Mbembe (2003, 2008). São muitos os 
autores que têm denunciado as precárias condições de vida das travestis. Na infância e adolescência enfrentam violência e o abandono familiar. Em geral, não se adaptam e abandonam a escola precocemente e, além disso, enfrentam a falta de oportunidades de empregos. O desfecho desta trajetória de vida tem a atividade de prostituição como uma das poucas alternativas de sobrevivência (ALBUQUERQUE, 2005; BASKERVILE, 2012; BENEDETTI, 2005; BOULEVARD, 2013; LEE, 2013; NIKARATTY, 2013; ORNAT, 2009, 2012； PELÚCIO, 2009; PERES, 2005; RIQUELME, 2013; SANTOS, 2010; SILVA, 1993, 1996, 2007; 2009).

As mortes das travestis, mesmo as prematuras e violentas não são lamentadas para a sociedade brasileira, segundo Cabral, Silva e Ornat (2013). Pelo contrário, em geral, as travestis são culpabilizadas pela própria morte pelo fato de estarem envolvidas em situações de risco, a sociedade acha que é natural que elas acabem sendo vítimas de tragédias. O trabalho de Silva e Rodó-de-Zárate (2015) evidencia que o fato das travestis brasileiras vivenciarem a morte de pessoas próximas de seu círculo de amizades faz com que elas não projetem seu futuro contemplando o processo de envelhecimento.

As travestis vivem vidas precárias conforme Butler (2004b) e a insensibilidade social diante de tantas vidas eliminadas é resultado da desconsideração de sua humanidade. O poder normativo organiza a lógica das vidas vivíveis e das mortes lamentáveis socialmente, mostrando à sociedade quem são percebidos como seres importantes ou não.

Mesmo assim, as travestis brasileiras estabelecem uma série de práticas que tornam suas vidas vivíveis. Silva e Rodó-de-Zárate (2015) afirmam que os territórios de prostituição e as Organizações Não Governamentais são apontadas pelas travestis brasileiras como espaços de alívio da opressão das normas de gênero e onde elas se sentem confortáveis consigo mesmas. São estas espacialidades de conforto para as travestis em que estão pautadas as recentes discussões sobre a prevenção da organização das redes internacionais de prostituição e sua criminalização, como será evidenciado a seguir. 


\section{As Políticas de Prevenção da Organização das Redes de Prostituição e a Ininteligibilidade das Travestis Brasileiras}

O efeito desumanizador das travestis não se institui apenas por sua morte física, mas pela concepção de um ser irreal na esfera pública. A esfera pública, conforme Butler (2004b), controla a forma como essas pessoas devem ser vistas e interpretadas. As políticas públicas criadas para prevenção da imigração ilegal e das redes de prostituição internacionais possuem uma concepção que opõe o bem e o mal, vítima e criminoso, legal e ilegal. Esse padrão interpretativo da realidade social não consegue captar a complexidade da realidade das travestis brasileiras que desenvolvem práticas que não podem ser enquadradas de forma simples em um dos dois polos.

No ano de 2006 o governo brasileiro aprovou o I Plano Nacional de Combate ao Tráfico de Seres Humanos para responder aos crescentes debates e exigências de várias organizações internacionais como as Nações Unidas, a Organização Internacional do Trabalho. Este plano estabeleceu diretrizes de ações para o Brasil entre 2007-2010 que foi sucedido pelos dois planos seguintes. O segundo, executado entre 2011-2013 e o terceiro plano nacional tem ações para serem desenvolvidas no período de 2014-2017. As políticas de governo mencionadas atingem a realidade das travestis, já que um dos focos mais importantes dos planos tem relação com o trabalho sexual e suas formas de organização.

Os três planos nacionais estão estreitamente conectados com as políticas internacionais envolvendo a migração e a prostituição, amplamente debatida por vários pesquisadores que evidenciam o caráter moral da migração internacional ligada à prostituição travesti, notadamente quando o fluxo ocorre dos países mais pobres para os países mais ricos. (ver HOWE, ZARAYSKY, e LORENTZEN, 2008; LEWIS, 2012). Os planos nacionais têm em comum a preocupação com os direitos humanos e conjugam, de um lado, as ações de repressão ao tráfico de seres humanos com fins de exploração sexual e, de outro, a prevenção e o apoio a vítima. (BRASIL, 2006, 2010, 2013).

Os países receptores de imigrantes que exercem o trabalho sexual, por sua vez, também organizam suas ações com base nos princípios da repressão, prevenção e apoio às vítimas do tráfico de seres 
humanos, como é o caso da Espanha, por exemplo, um dos destinos preferenciais das travestis brasileiras nas duas primeiras décadas do século XXI, conforme Silva e Ornat (2015).

As parcerias estabelecidas entre países emissores e receptores de pessoas envolvidas em redes de prostituição internacional carecem, no entanto, do estabelecimento de compreensão da realidade em que as pessoas constituintes das redes estão envolvidas. A Asociación para la Prevención, Reinserción y Atención a la Mujer Prostituida $(\mathrm{APRAMP})^{4}$, instituição envolvida no combate ao tráfico de pessoas, sediada em Mardri, expressa suas preocupações em relação as redes de prostituição brasileiras, tanto como as do leste europeu. Segundo responsável pela instituição,

as máfias são diferentes em cada lugar. Hoje temos aqui o problema com aquelas que vêm do leste europeu como da Polônia e Romênia e também com a máfia brasileira. Elas funcionam de forma diferente uma da outra. A máfia do leste europeu parece ser mais organizada e mais perigosa do que as máfias brasileiras que são mais informais e menores. (Entrevista realizada com Rocío Nieto, responsável pela APRAMP, em Madri - Espanha, em 05 de maio de 2008)

Outra importante instituição, o Colectivo de Lesbianas, Gays, Transexuales y Bisexuales de Madrid (COGAM), conta com uma seção específica para mulheres trans e esclarece as dificuldades de acesso às dinâmicas de prostituição internacionais que envolvem as imigrantes.

Nós somos contra qualquer tipo de tráfico e exploração sexual. Nós queremos que o trabalho sexual seja reconhecido como trabalho e que a pessoa que quiser exercer essa atividade faça isso com liberdade e tenha direitos sociais. Mas veja bem, a maior parte das pessoas que se prostituem aqui não imigrantes. Assim, a regularização do trabalho sexual para as pessoas que estão ilegalmente no país é complicada. Nós apenas temos acesso às que estão nas ruas, mas as brasileiras, em geral, estão nos pisos e nós não temos muito acesso a elas. Para ajudar essas pessoas precisamos que elas venham até nós. Mas é difícil porque elas já trazem a consciência da exclusão de seus próprios países e não procuram muito a gente. (Entrevista realizada Lizeth Álvarez, responsável pelo Grupo de Transexuais de COGAM, em Madri - Espanha, em 08 de junho de 2008)

\footnotetext{
${ }^{4}$ Importante dizer que apesar desta instituição priorizar as mulheres cis, atualmente ela também contempla as mulheres trans, conforme a pessoa entrevistada. Ver: http://apramp.org/
} 
Ambas as instituições espanholas que colaboraram com esta pesquisa apontam seus limites na compreensão e capacidade de ação junto as travestis brasileiras que organizam redes de prostituição na Espanha. A COGAM que luta pela legalização do trabalho sexual encontra dificuldades para desenvolver ações que tragam maior segurança para as travestis brasileiras. Isso porque a regularização do trabalho sexual implica também tratar da imigração ilegal e este é um tema bastante polêmico nos países europeus na atualidade. A APRAMP, por sua vez, compreende as redes de prostituição brasileiras como máfias, o que não corresponde a organização do trabalho sexual das travestis.

A maior parte dos planos de ação para prevenção ao tráfico de seres humanos para fins de exploração sexual e também a imigração ilegal estão apoiados no trabalho das Organizações Não Governamentais. Espera-se que as ONGs possam fazer o trabalho de sensibilização e prevenção aos processos de prostituição internacional. Contudo, as travestis que fazem parte das ONGs de direitos humanos são as mesmas que organizam as redes de prostituição, constituindo assemblages no sentido proposto por Puar (2007). A desconsideração das formas de vida das travestis brasileiras constitui uma série de violências e alto potencial de criminalizá-las ainda mais.

Várias travestis mais velhas, militantes do movimento político de travestis e transexuais conquistaram respeitabilidade. Com o processo de envelhecimento, acabaram se tornando 'donas de pensionato' para travestis $^{5}$. Essa denominação é dada para travestis mais velhas conseguem estabelecer seu negócio por terem adquirido ao longo da vida o domínio das práticas de prostituição e uma trajetória de respeito entre as demais travestis. Tal trajetória de respeito também se faz da militância no movimento político por direitos humanos.

\footnotetext{
5 A denominação 'dona de pensionato' é recente e vem sendo utilizada para designar pessoas que prestam serviços para as travestis no exercício da prostituição. 0 termo tem sido uma estratégia política de substituir o termo 'cafetina', já que este último denomina uma atividade criminosa.
} 
A interseção entre o prestígio nas redes do movimento de direitos humanos de travestis e trans e ser uma 'dona de pensionato' acaba por constituir um processo relacional que potencializa a organização e eficácia das redes de prostituição tanto em nível nacional como internacional. A fala de Erina ${ }^{6}$ é ilustrativa da imbricação do poder das 'donas de pensionatos' nas organizações políticas travestis e a forma como essa interseção potencializa seu negócio:

Ela [referindo-se a dona de pensionato] me explicou tudo certinho quando a gente tava no Encontro Nacional de Travestis e Transexuais na Luta Contra a AIDS lá no Rio de Janeiro. Ela está montando um apartamento lá na Espanha. Porque daí ela vai mandar para lá as meninas que estão na pensão dela, as que querem ir para lá e isso é bom. Por isso eu te digo, isso não é cafetinagem, é uma oportunidade para nós. (Entrevista realizada com Erinia, Brasil, em 30 de julho de 2010).

As redes de conhecimento possibilitam a indicação de nomes, endereços e telefones que constituem uma importante fonte de troca de informações nesse ramo de atividade do comércio sexual. Mesmo que as redes de conhecimento pessoal possam ser consideradas caóticas elas são extremamente eficientes e garantem seu próprio processo de reprodução, tanto na escala nacional como internacional.

As estratégias de deslocamentos internacionais ocorrem com o empréstimo em somas em dinheiro, adiantamentos para compra de passagens aéreas e preparação de documentação, bem como facilitações de entrada em países da Europa, em geral, Itália, Espanha e Portugal. A dívida contraída é cobrada posteriormente com valores que muitas vezes ultrapassam o dobro daquilo que foi emprestado como já visto em Silva e Ornat (2015).

As estratégias para deslocamentos internacionais se dá a partir de redes de interdependência que estabelecem códigos culturais próprios de inteligibilidade do fenômeno como evidenciado pela travesti Estige:

A polícia muitas vezes não entende o mundo da gente, sabe. Eles acham que é crime o que a gente faz. Eles não entendem. Dizem que uma pessoa que tem uma casa e, por exemplo, recolhe

\footnotetext{
${ }^{6}$ Todos os nomes são fictícios.
} 
uma travesti, investe nela e depois quer o dinheiro que investiu de volta é cafetinagem. Mas veja, vem uma travesti, quer colocar peito, quer uma peruca e você ajuda ela se montar e ensina a vida para ela. Como faz o serviço, como se defender, como ser uma travesti. Você faz a travesti e depois, é claro, quer o que investiu de volta. Imagina, uma pessoa que geralmente nem a mãe quer, a família rejeita e só tem a gente. Mas a polícia não entende a gente, como é que é a vida da gente e acha que isso é crime. Mas não é. É a forma como a gente vive, como podemos viver. (Entrevista realizada com Estige, em Madri - Espanha, em 14 de maio de 2008).

A fala de Estige evidenciada aqui reflete a síntese discursiva das entrevistadas que colocam a 'dona de pensionato' como uma pessoa que auxilia as travestis que estão em situação de exclusão e vulnerabilidade na organização de redes de prostituição que lhes permite sobreviver e até mesmo conquistar melhores condições de vida com o acesso a outros países.

As 'donas de pensionatos' exercem de forma relacional uma centralidade na organização de redes de prostituição travesti, bem como são importantes figuras no movimento político das travestis e transexuais. A complexidade das ações das 'donas de pensionatos' é analisada pelas travestis que as legitimam, como pode ser visto a seguir.

Então, tem umas que vem aqui [referindo-se as donas de pensionatos para travestis] e falam de direitos humanos. Mas elas batem nas travestis que ficam devendo pra elas ou que não obedecem as regras delas. São terríveis. Então é complicado, mas é assim que o mundo é porque elas tem que colocar ordem nas coisas para não sair do controle dela. É estranho né porque a [nome ocultado] mandou quebrar a casa da [nome ocultado] falando que ela saiu da pensão dela devendo dinheiro. Mandou quebrar tudo só pra dar uma lição e é assim que as coisas funcionam. Daí ela vem nos encontros das ONGs e fala da violência da polícia. É estranho né. (Entrevista realizada com Isis, Brasil, em 30 de julho de 2008.)

O movimento político de travestis e transexuais brasileiras devem ser compreendidas como parte das vidas precárias que as travestis vivem e que suas ações são estratégias de luta dentro do contexto de vulnerabilidade do grupo. Ao contrário do que concebem as políticas de combate ao tráfico de seres humanos, as Organizações Não Governamentais de travestis e transexuais brasileiras não estão fora do processo da organização das redes de prostituição, mas são inerentes a ele como forma de tornar 
suas vidas vivíveis. Privadas de rosto e de capacidade de discussão das concepções normativas, as travestis brasileiras constituem uma legião de vidas invisíveis.

\section{Entre a Exploração e o Acolhimento: Travestis Tornando suas Vidas Vivíveis}

O jogo que se estabelece entre as versões dos discursos sobre imigração para o trabalho sexual e 0 tráfico de seres humanos tem sido desvantajoso para as travestis brasileiras, já que o conhecimento por elas produzido é desconsiderado e a forma como elas tornam suas vidas precárias vivíveis é invisível (STRYKER, 2006).

A ininteligibilidade das vidas das travestis brasileiras se dá pela perpetuação das concepções ocidentais imperiais nas concepções da realidade, conforme argumenta Mignolo (2009). Segundo ele, é preciso aprender a desaprender os conhecimentos que negaram a humanidade a determinados seres humanos e que ainda orienta o olhar de quem tem o privilégio da enunciação de verdades. As travestis são vítimas da percepção arrogante, para usar os termos de Lugones (1987), que constitui a academia e também as instituições de justiça. Contudo, segundo esta autora,

Through travelling to other people's 'worlds' we discover that there are 'worlds' in wich those who are the victims of arrogant perception are realyy subjects, lively beings, resistors, constructors of visions even thought in the mainstream construction they are animes only by the arrogant perceiver and are pliable, foldable, file-awayable, classifiable. (LUGONES, 1987, p. 18)

As travestis brasileiras resistem e criam, apesar de suas vidas precárias, formas específicas de viver e compreender sua existência. Elas não podem ser classificadas apenas como vítimas e ou criminosas. As travestis têm plena consciência dos elementos e jogos envolvidos na estruturação das redes de prostituição internacionais e nacionais, como pode ser visto na fala de Talia a seguir.

Olha, eu estou nessa vida há muito tempo e posso te afirmar. Todas nós que estamos aqui [referindo-se a Espanha] viemos dessa forma aí que eles dizem que é tráfico. Todas! Nós dependemos disso para vir. Fazemos os acordos necessários e pronto. Entramos no jogo que 
sabemos como é. Quem não cumpre a palavra leva um 'doce' ${ }^{7}$. E vou te dizer que quem ajuda a gente a vir são pessoas que a gente acaba devendo muito. Não é só o dinheiro, mas é a gratidão também, sabe. Ela te ajudou como ninguém mais te ajuda sabe. (Entrevista realizada com Talia, em Madrid- Espanha em 18/05/2008)

As redes que se instituem para o agenciamento de travestis brasileiras contém elementos que envolvem afetividade e confiança, mas não a ingenuidade das regras do jogo que vão assumir. As relações que se estabelecem entre as travestis e as 'donas de pensionatos' não são puramente comerciais, mas também de acolhimento, cuidados e, sobretudo, de cumprimento das regras instituídas pelo código moral do grupo. A interseção entre ser uma 'dona de pensionato' e fazer parte do movimento político de trans facilita o estabelecimento de várias ações que facilitam a existência das travestis em sua atividade de prostituição, como pode ser visto na fala de Afrodite, uma notável 'dona de pensionato' para travestis:

Aqui na casa eu dou o básico, casa e comida. Aí a gente tenta procurar saúde, fazer os exames para ter a saúde em ordem. Como eu trabalho na ONG, aí eu tenho acesso a preservativos e trago para as meninas. Quando eu vou nas reuniões, eu já trago pra elas. (...) Também ajudo com a documentação, porque muitas chegam aqui em casa sem documento. Não tem como uma pessoa viver sem documento, não é? (Entrevista realizada com Afrodite, no Brasil, em 31 de julho de 2008).

As 'donas de pensionatos' recebem as travestis em suas casas e conseguem suprir uma série de serviços para o funcionamento da prostituição, em troca de um pagamento diário. Além de abrigo e alimentação, as 'donas de pensionatos' também garantem a segurança nas ruas da cidade onde elas dominam as relações de poder no território da prostituição. Outro serviço importante é o estabelecimento de contatos com outras 'donas de pensionatos' localizadas em outras cidades do Brasil e também do exterior. Isso possibilita a rotatividade das travestis entre cidades. Isso, por sua vez, aumenta seus lucros, já que os clientes da prostituição gostam das 'novidades'. Além disso, as 'donas de pensionatos' viabilizam as transformações corporais como cirurgias plásticas e injeção de silicone

\footnotetext{
${ }^{7} \mathrm{O}$ 'doce' é uma metáfora utilizada pelo grupo que significa alguém que manda encomendar uma 'surra' para a pessoa que descumpriu as regras do jogo
} 
industrial $^{8}$, mediante empréstimos de somas de dinheiro que as travestis devem devolver em quantidades bem superiores do que elas receberam ${ }^{9}$.

As pessoas entrevistadas que se autodenominam 'donas de pensionatos' rejeitam a palavra 'cafetina' para definir sua atuação. Consideram seu trabalho uma forma de auxiliar as travestis jovens em sua sobrevivência em uma sociedade em que elas não são respeitadas.

Eu não acho que eu as estou explorando. Mas eu gosto de ajudar, se eu for presa, eu vou atrás dos meus direitos (...) Uma pessoa que tenha uma casa como eu tenho, como a [nome de dona de pensionato ocultado] em [nome da cidade ocultado] tem também, a [nome de dona de pensionato ocultado] em [nome da cidade ocultado] tem e muitas outras, somos vistas como cafetinas, mas nós não somos. (Entrevista realizada com Atena, no Brasil, em 26 de maio de 2009).

As travestis entrevistadas defendem a mesma posição, organizando um discurso de que as 'donas de pensionatos' auxiliam sua difícil vida diária como profissionais do sexo e que elas facilitam seus deslocamentos por diversas cidades, como fala Erina:

eu não vejo como cafetinagem [referindo-se as donas de pensionatos]. Para mim a cafetinagem é quando você coloca a pessoa na rua e pega tudo que ela ganhar, entende. Ela não, ela está cobrando por um serviço, por cama, alimentação e proteção (...). É assim que elas dizem, se você ficou na minha casa, você tem a garantia da rua. Eu acho que é melhor assim, porque antes a gente pagava a cafetina e ainda tinha que pagar para os gigolôs das outras travestis. Assim não, estou mais segura. (Entrevista realizada com Erinia, no Brasil, em 30 de julho de 2010).

A lógica que organiza o discurso das travestis em torno das 'donas de pensionatos' reflete elementos que ultrapassam a lógica puramente econômica, mas de respeito pela trajetória de vida, um modelo de sucesso, acolhimento e afeto. A autoridade, muitas vezes estabelecida na forma de violência física é considerada perfeitamente compreendida como necessária nas relações de poder que envolvem o grupo para a manutenção da ordem. As 'donas de pensionatos' são referenciadas pelas travestis como 'mães'

\footnotetext{
${ }^{8}$ Injeção de silicone industrial é uma prática considerada ilegal, mas ainda bastante utilizada pelo grupo para atingir as forma femininas do seus corpos.

9 Elas argumentam que os bancos cobram juros altos também e ainda exigem garantias. Elas fazem as negociações considerando que as travestis não possuem documentos e comprovação de rendimentos.
} 
e as travestis que elas acolhem em suas casas são chamadas de 'filhas'. Isso significa que é necessário dominar os códigos específicos de valores do grupo para ascender como elas conquistam prestígio e garantem sua posição nessas redes de deslocamentos, como explica Iris:

\footnotetext{
É assim por exemplo, se eu tô em [nome da cidade] na casa de uma cafetina que manda na cidade e eu queri ir para [nome de cidade]. Aí, como ela conhece a travesti que comanda a cidade que eu quero ir, ela me indica para lá. Na maioria das vezes, elas próprias ligam e falam assim; 'Olha, eu estou mandando uma filhinha minha pra ficar um tempo com você, cuida dela aí!' Então é assim sabe, uma cafetina indica pra outra cafetina. É tipo uma rede. Aqui é uma rede nacional. Mas tem as que vão pra Europa e elas já vão para lá com lugar certo para trabalhar lá e assim é bem melhor porque vão ter onde morar e ter segurança. (Entrevista realizada com Iris, no Brasil, em 8 de agosto de 2008).
}

Integrar essas redes de pessoalidade significa para as travestis brasileiras a inclusão em um espaço de proteção frente a violência que faz parte de sua vida diária. Mas além disso, uma possibilidade de ascender econômica e socialmente em um contexto de extrema exclusão.

\section{Considerações Finais}

Este artigo explorou as contradições entre as formas de organização das redes de prostituição das travestis brasileiras e a constituição de normas de regulação que desconsidera o seu contexto de existência. As travestis brasileiras estão submetidas a violência normativa institucionalizada, tanto na escala nacional como internacional. A violência normativa, como propõe Butler (2004b), acaba por fazer com que a violência física contra as travestis seja naturalizada e invisibilizada. A violência contra as travestis não é compreendida socialmente como violência, mas apenas como sendo uma resposta àqueles que transgridem as regras sociais. A baixa expectativa de vida das travestis brasileiras é um problema social e político que necessita ser assumido conjuntamente em seu aspecto estrutural da precariedade de suas vidas. Entretanto, para trazer este tema para a constituição de normas que tornem a vida de travestis brasileiras vivíveis, é necessário conhecê-las se desvencilhando da 
percepção arrogante (que só faz constituir a violência epistêmica sobre elas) e criando uma loving perception capaz de reconhecer suas capacidades e sua humanidade como propõe Lugones (1987).

\section{REFERÊNCIAS}

ALBUQUERQUE, Fernanda Farias de. A Princesa: a história do travesti brasileiro na Europa escrita por um dos líderes da Brigada Vermelha. Rio de Janeiro: Nova fronteira, 1995.

AUGUSTÍN, Laura María. Sex at the margins: migration, labour markets and the rescue industry. London \& New York: Zedbooks, 2007.

ANTUNES, Pedro Paulo Sammarco. “Travestis envelhecem?” Dissertação (Programa de Estudos Pós-Graduados em Gerontologia), Pontifícia Universidade de São Paulo, 2010.

BALZER, Carsten (Carla La Gata); HUTTA, Jan Simon; ADRIÁN, Tamara; HYLDAL, Peter; STRYKER, Susan. Transrespect versus transphobia worlwide. A comparative review of the Human Rights Situation of gender-variant / Trans People. Berlin: Transgender Europe (TGEU), 2012.

BASKERVILLE, Nelson. Luis Antônio - Gabriela. São Paulo: Nversos, 2012.

BENEDETTI, Marcos Renato. Toda feita: o corpo e o gênero das travestis. Rio de Janeiro: Garamond, 2005

BOULEVARD, Gláucia. Vida de travesti é luta! Luta contra a morte, luta contra o preconceito, luta pela sobrevivência e luta por espaço. In: SILVA, Joseli Maria; ORNAT, Marcio Jose; CHIMIN JUNIOR, Alides Baptista. Geografias malditas: corpos, sexualidades e espaços. Ponta Grossa: Todapalavra, 2013, p. 69 - 81.

BRASIL. I Plano Nacional de Combate ao Tráfico de Seres Humanos. Brasília. 2006.

BRASIL. II Plano Nacional de Combate ao Tráfico de Seres Humanos. Brasília. 2010.

BRASIL. III Plano Nacional de Combate ao Tráfico de Seres Humanos. Brasília. 2013.

BUTLER, Judith. Undoing gender. New York / London: Routledge, 2004a.

BUTLER, Judith. Precarious life: the powers of mourning and violence. London /

New York: Verso, 2004b.

CABRAL, Vinícius; SILVA, Joseli Maria; ORNAT, Marcio Jose. Espaço e morte nas representações sociais de travestis. In: SILVA, Joseli Maria; ORNAT, Marcio Jose; CHIMIN JUNIOR, Alides Baptista. Geografias malditas: corpos, sexualidades e espaços. Ponta Grossa: Todapalavra, 2013, p. 246 - 275.

GRUPO DAVIDA. Prostitutas, 'traficadas' e pânicos morais: uma análise da produção de fatos em pesquisas sobre o 'tráfico de seres humanos'. Cadernos Pagu, v. 25, p. 153 -184, 2005.

GRUPO GAY DA BAHIA. Assassinato de homossexuais no Brasil. Relatório anual do Grupo Gay da Bahia. Fonte: <http://www.ggb.org.br/assassinatos\%20de\%20homossexuais\%20no\%20brasil\%202011\%20GGB.html>. Acesso em 12 de março de 2016. 2014.

HOWE, Cymene; ZARAYSKY, Susanna; LORENTZEN, Lois. Transgender Sex Workers and Sexual Transmigration between Guadalajara and San Francisco. Latin American Perspectives, v. 35, n. 1, p. 31 - 50, 2008. 
KEMPADO0, Kamala. Victims and agents of crime: the new crusase against Trafficking. In: SUDBURY, Julia. Global Lockdown: Race, Gender, and the Prison-Industrial Complex. New York: Taylor and Francis Books, 2005, p. 35 - 56.

KEMPADO0, Kamala; SANGHERA, Jyoti; PATTANAIK, Bandana. Trafficking and prostitution reconsidered. New perspectives on migration, sex work and human rights. London: Paradigm Publishers, 2005.

KARRAKER, Wilkers. The Other People: Interdisciplinary Perspectives on Migration. New York: Palgrave Macmillan, 2013.

LEE, Debora. 2013. A geografia de uma travesti é uma barra, é matar um leão a cada dia. In: SILVA, Joseli Maria; ORNAT, Marcio Jose; CHIMIN JUNIOR, Alides Baptista. Geografias malditas: corpos, sexualidades e espaços. Ponta Grossa: Todapalavra, 2013, p. $27-38$.

LEWIS, Vek. Crossing Sex and Gender in Latin America. New York: Palgrave Macmillan, 2010.

LEWIS, Vek. Volviendo visible o invisible: hacia un marco conceptual de las migraciones internas trans en México. Cuicuilco, v. 54, p. $219-240,2012$.

LUGONES, Maria. Playfulness, 'World' - Travelling, and Loving Perception. Hypatia, v. 2, n. 2, p. 3 - $19,1987$.

MBEMBE, Achille. Necropolitics. Public Culture, v. 15, n. 1, p. 11 - 40, 2003.

MBEMBE, Achille. Necropolitics. In: MORTON, Stephen; BYGRAVE, Stephen. Foucault in an Age of Terror. Essays of biopolitics and defense of society. New York: Palgrave, 2008, p. $152-182$.

MIGNOLO, Walter. Epistemic Disobedience, Independent Thought and De-Colonial Freedom. Theory, Culture \& Society, v. 26, n. 7 - 8, p. 1 - 23, 2009

NIKARATTY, Leandra. O que mais me marcou na vida é ser barrada e não poder entrar nos lugares: esta é a geografia de uma travesti. In: SILVA, Joseli Maria; ORNAT, Marcio Jose; CHIMIN JUNIOR, Alides Baptista. Geografias malditas: corpos, sexualidades e espaços. Ponta Grossa: Todapalavra, 2013, p. 239 - 54.

ORGANIZAÇÃO DAS NAÇÕES UNIDAS. Protocolo Adicional à Convenção das Nações Unidas contra a Criminalidade Organizada Transnacional relativo à Prevenção, à Repressão e à Punição do Tráfico de Pessoas em especial de Mulheres e Crianças de Palermo. Fonte: <www.unodc.org >. Acesso em 12 de março de 2016. 2000.

ORNAT, Marcio Jose. Espacialidades travestis e a instituição dos territórios paradoxais. In: SILVA, Joseli Maria.

Geografias Subversivas: discursos sobre espaço, gênero e sexualidades. Ponta Grossa: Todapalavra, 2009, p. 177 - 210.

ORNAT, Marcio Jose. Espaços interditos e a constituição das identidades travestis através da prostituição no Sul do Brasil. Revista Latino-americana de Geografia e Gênero, v. 3, n. 1, p. 54 - 73. 2012.

PELÚCIO, Larissa. Abjeção e desejo: uma etnografia travesti sobre o modelo preventivo de aids. São Paulo: Annablume, 2009.

PERES, Wiliam Siqueira. Travestis Brasileiras: Construindo identidades cidadãs: movimentos sociais, educação e sexualidades. Rio de Janeiro: Garamond Universitária, 2005.

PUAR, Jasbir K. Terrorist Assemblages in queer times. Durham: Duke University Press, 2007. 
RIQUELME, Fernanda. 2013. A vida da travesti é glamour, mas também é violência em todo lugar. In: SILVA, Joseli Maria; ORNAT, Marcio Jose; CHIMIN JUNIOR, Alides Baptista. Geografias malditas: corpos, sexualidades e espaços. Ponta Grossa: Todapalavra, 2013, p. 55 - 68.

SANTOS, Paulo Reis dos. Desejos, conflitos e preconceitos na constituição de uma travesti no mundo da prostituição. Revista Latino-americana de Geografia e Gênero, v. 1, n. 1, p. 39 - 48, 2010.

SHARMA, Nandita. Anti-Trafficking Rhetoric and the Making of a Global Apartheid. NWSA Journal, v. 17, n. 3, p. 88 111,2005 .

SILVA, Hélio. Travesti: a invenção do feminino. Rio de Janeiro: Relume-Dumará, 1993.

SILVA, Hélio. Certas cariocas: travestis e vida de rua no Rio de Janeiro. Rio de Janeiro: Relume-Dumará, 1993.

SILVA, Hélio. Travestis: entre o espelho e a rua. Rio de Janeiro: Rocco, 2007.

SILVA, Joseli Maria. A cidade dos corpos transgressores da heteronormatividade.” In: SILVA, Joseli Maria. Geografias Subversivas: discursos sobre espaço, gênero e sexualidades. Ponta Grossa: Todapalavra, 2009, p. 135 - 150.

SILVA, Joseli Maria; RODÓ-DE-ZÁRATE, Maria. Brazilian travestis making lives liveable in their processes of ageing and death. Texto apresentado no encontro da Royal Geographic Society - Institute British Geographers, Annual International Conference, Exeter, UK, 3 de Setembro, 2015.

SILVA, Joseli Maria; ORNAT, Marcio Jose. Intersectionality and Transnational Mobility Between Brazil and Spain in Travesti Prostitution Networks. Gender, Place, and Culture: A Journal of Feminist Geography, v. 22, n. 8, p. 1073 - 1088, 2015.

STRYKER, Susan. (De)subjugated knowledges: An introduction to transgendered studies. In: STRYKER, Susana; WHITTLE, Stephen. The transgender studies reader. New York: Routledge, 2006, p. 1 -18. 